\title{
A borda do nó de Bispo do Rosário
}

\author{
Glaucia Nagem de Souza
}

\begin{abstract}
Resumo
Em 1975, Lacan pergunta: "Em que a arte, ou o artesanato, pode desfazer, se assim posso dizer, aquilo que se impõe do sintoma?” A partir dessa questão, o artigo aborda a obra criativa do artista brasileiro Arthur Bispo do Rosário. Ele trabalhou de modo constante, implacável e obrigatório para manter-se amarrado. Aos 29 anos, surta e passa por diversas internações. Até que, com sua arte, consegue um lugar diferenciado dentro do hospital psiquiátrico e é descoberto por um crítico de arte, que o inclui no cenário da arte contemporânea brasileira e internacional. Seria o enlace da arte de Bispo do Rosário um trabalho possível, em que a correção do nó incluiu em seu arcabouço o local onde ele trabalhava e o trabalho da saúde mental? O artigo interroga se seriam efeitos do que se aborda como adventos do Real a partir da teorização que Lacan desenvolveu nos anos 1970 sob o olhar de alguns comentadores contemporâneos, como Michel Bousseyroux e Rithée Cevasco.
\end{abstract}

\section{Palavras-chave: \\ Bispo do Rosário; Teoria dos nós; Nó de Whitehead; Falasser; Nomeação; Saúde mental. \\ The edge of the knot of Bispo do Rosário}

\begin{abstract}
In 1975, Lacan inquires: "In what can art, craft, undo, if I may say so, what is imposed on the symptom?" From this query, the article addresses the creative work of Brazilian artist Arthur Bispo do Rosario. He worked steadily, structurally, and mandatorily to remain stable. At the age of 29 he outbreaks and goes through various hospitalizations. Until, because of his art, he obtains a differentiated place inside the psychiatric hospital and is discovered by an art critic that includes him in the scene of the contemporary Brazilian and international art. Was the link of the art of Bispo do Rosário a possible work where the knot correction included in his framework the place where he worked and the work of mental health? Are they effects of what we are addressing as the advent of the real in his work and
\end{abstract}


the effects in the space of the hospital? These issues will be approached from the theorization Lacan developed in the 1970s, under the watchful eye of some contemporary commentators such as Michel Bousseyroux and Rithée Cevasco.

\section{Keywords:}

Bispo do Rosário; Theory of knots; Whitehead's knot;

Parlêtre; Naming; Mental health.

\section{El borde del nudo de Bispo do Rosário}

\section{Resumen}

En 1975, Lacan pregunta: “En qué el arte, o la artesanía, puede deshacer, si así puedo decir, lo que se impone del síntoma?” A partir de esta cuestión, el artículo aborda la obra creativa del artista brasileño Arthur Bispo do Rosario. Él trabajó de modo constante, impactante y obligatorio para mantenerse estabilizado. A los 29 años él brota y pasa por diversas internaciones. Hasta que por su arte logra un lugar distinguido dentro del hospital psiquiátrico y lo descubre un crítico de arte que lo incluye en el escenario del arte contemporáneo brasileño e internacional. ¿Sería el enlace del arte de Bispo do Rosário un trabajo posible donde la corrección del nudo incluyó en su armazón el lugar donde él trabajaba y el trabajo de la salud mental? ¿Serían efectos de lo que estamos abordando como advenimiento de lo Real en su obra y los efectos en el espacio del hospital? Estas cuestiones se abordarán a partir de la teorización que Lacan desarrolló en los años 70, bajo la mirada de algunos comentaristas contemporáneos como Michel Bousseyroux y Rithée Cevasco.

\section{Palabras claves:}

Bispo do Rosário; Teoría de los nudos; Nudo de Whitehead;

Parlêtre; Nombramiento; Salud mental.

\section{Le bord du nœud de Bispo do Rosário}

\section{Résumé}

En 1975, Lacan demande : " En quoi l'art, l'artisanat peut-il déjouer ce qui s'impose du symptôme à savoir la vérité ?». À partir de cette question, cet article réfléchi à propos du travail de création de l'artiste brésilien Arthur Bispo do Rosário. Celui-ci a travaillé constamment, et de façon implacable et obligatoire, pour se maintenir stable. À l'âge de 29 ans, il a un moment de rupture, et est hospitalisée 
maintes fois, jusqu'à ce que son art obtienne une place importante au sein de l'hôpital psychiatrique, et qu'il soit découvert par un critique d'art qui l'inclut dans la scène de l'art brésilien et international contemporain. Serait-ce le nouage de l'art de Bispo do Rosário un travail possible, où la correction du nœud a inclut dans sa structure la place où il travaillait et le travail de la santé mentale ? Cet article interroge si cela ne sont pas des effets de ce qu'on comprend d'habitude comme avènements du Réel, à partir de la théorisation développée par Lacan dans les années 1970, sous le regard de quelques commentateurs contemporains tels que Michel Bousseyroux et Rithée Cevasco.

\section{Mots-clés :}

Bispo do Rosário ; Théorie des nœuds ; Nœud de Whitedead ; Parlêtre ; Nomination; Santé mentale.

\section{Um pouco da história de Bispo}

Arthur Bispo do Rosário foi considerado pela crítica um artista brasileiro comparável a Marcel Duchamp. Se, para a arte, ele teve esse lugar, ele mesmo não se ligava a isso - diferentemente de James Joyce, que se nomeava artista e, com isso, segundo Lacan, teria "corrigido" seu nó a partir desse ego de artista, como acompanhamos no Seminário 23, dedicado ao escritor (Lacan, 1975-1976/2007).

Quando já estava internado havia 50 anos, foi descoberto por uma reportagem que mostrava os horrores da vida no manicômio. Seu trabalho, no entanto, começou muito antes, quando do surto em que recebeu a ordem divina para fazer um recenseamento do mundo para apresentar no Juízo Final. Foi internado após o convencimento de seus patrões da época e, nos anos de internação, chegou a ocupar 10 celas com sua obra.

De seu surto, temos o registro feito por ele mesmo no texto bordado, no qual relata o acontecido para ele naquela antevéspera de Natal: ${ }^{1}$

22 DEZEMBRO 1938 - MEIA NOITE ACOMPANHADOO POR - 7 ANJOS EM NUVES ESPECIAS FORMA ESTEIRA - MIM DEIXARAM NA CASA NOS FUNDO MURRADO RUA SÃO CLEMENTE - 301 BOTAFOGO ENTRE AS RUAS DAS PALMEIRAS E MATRIS EU COM LANÇA NAS MÃO NESTA NUVES ESPÍRITO MALISIMO NÃO PENTRARA AS 11 HORAS ANTES DE IR AO CENTRO DA CIDADE NA

1 Os textos recolhidos de seus estandartes e mantos são retirados da biografia Arthur Bispo do Rosário: o senhor do labirinto, de Luciana Hidalgo (1996). Neles, é mantido o modo de escrita de Bispo, com sua grafia, que inclui erros e está, na maior parte, em letras maiúsculas. 


\begin{abstract}
RUA PRIMEIRO DE MARÇO - PRAÇA 15 - EU FIZ ORAÇÃO DO CLERO NO CORREDOR PERTO DA PORTA - VEIO MIM - HUMBERTO MAGALHAES LONI - ADVOGADO MESTRE PARA ONDE EU IA PERGUNTOU EU VOU MIM APRESENTAR - NA IGREJA DA CANDELÁRIA ESTA FOI MINHA RESPOSTA EU ABRIR A PORTA LADO LESTE UM JARDIM VARAS CORES AO 7... (Rosário citado por Hidalgo, 1996, p. 13)
\end{abstract}

Assim, Bispo escreve, com seus bordados, sobre o episódio em que inicia sua missão. Seus patrões o encontraram já internado e nas malhas do serviço psiquiátrico. Ele mesmo explicaria sua internação e o início do contato com os médicos, ou homens de capa branca, como os chamava:

Eu só me admiro aqui. É que quando eu vim pra cá e houve a junta de médicos, quando eu vim do Mosteiro de São Bento, o médico Dr. Odilon, e outros psiquiatras, quando perceberam, disseram: “O senhor é Deus!" E tem na minha ficha como esquizofrênico-paranoide. É erro! Erro médico porque, pela história do Sagrado Criador, médico-psiquiatra não existe. Médico, sim, psiquiatra, não. E o médico-psiquiatra me fazia isso, me dava remédio. $\mathrm{O}$ médico, quando é bom, quando percebe, não dá remédio. (Hidalgo, 1996, p. 21)

No verão de 1939, depois de algumas idas e vindas, Bispo é internado na Colônia Juliano Moreira sob o número 01662, e dali só sairia após sua morte. Mesmo quando sua obra foi exposta pela primeira vez, isso só foi possível pela negociação de Maria Amélia Mattei e Hugo Denizart, pois o próprio Bispo dizia que suas obras eram como filhos. Quando convidado para visitar sua exposição no Museu de Arte Moderna (MAM), no Rio de Janeiro, respondeu que seus olhos não estavam preparados para ver aquilo.

Após sua descoberta, o crítico de arte Frederico Moraes fez um movimento em prol da conservação e da exposição de sua obra. A partir dessa intervenção, o trabalho de Bispo chegou até mesmo a representar o Brasil em uma bienal de Veneza.

\title{
A aparição no mundo e a criação de sua obra
}

Quando perguntavam sobre sua origem, Bispo apenas respondia: "Um dia, eu apareci." Nos diferentes documentos, ora vemos o registro dos pais, ora não. $\mathrm{Na}$ Igreja de Japaratuba, onde seria sua cidade natal, consta: "Aos 5 de outubro de 1909 baptisei solemnemente, Arthur, com 3 mezes, legítimo de Claudino Bispo do Rosário e Blandina Francisca de Jesus. Foram padrinhos Maximiniano Ribeiro dos Santos e Candida dos Prazeres" (Hidalgo, 1996, p. 34). 
"Claudino", no registro da igreja, não coincide com "Adriano", nas fichas da Light e da Marinha. Da mãe, carrega o dom de ouvir as vozes desde menino. E o nome dela reverbera em seu manto da Anunciação bordado (Hidalgo, 1996, p. 142).

$$
\begin{aligned}
& \text { BELANISA-FRANCISCA - DE - JESUS } \\
& \text { ANGELINA - FRANCISCA -DE - JESUS } \\
& \text { CELETRINA - FRANCISCA -DE - JESUS } \\
& \text { ESMERALDA - FRANCISCA - DE - JESUS }
\end{aligned}
$$

Estava, assim, cravado no nome de cada mulher o sobrenome de sua mãe: Francisca de Jesus.

Pelos registros, sabe-se que, antes de trabalhar para os Leones e na Amiu, passou pela Marinha e pela Light. Tanto na casa dos Leones quanto com o dr. Bomfim, da Amiu, sempre houve um trato do que se apresentava em suas construções delirantes. Sua biografia conta que, na Amiu,

(...) discorria sobre a vida dos funcionários, reparava-lhes os defeitos, condenava almas. Rechaçava as mulheres que falavam alto e riam demais, não tolerava o excesso alheio. Dr. Bomfim entrava no jogo: "A sua aura está brilhando muito hoje, Bispo, tive até um arrepio quando lhe vi. Vai descansar um pouco." (Hidalgo, 1996, p. 72)

E, na família Leone, pôde manter-se com suas leituras delirantes sem muito incômodo, sendo por vezes até mesmo entendido como um contato sobrenatural.

\section{Seu corpo}

Bispo desempenhou, na juventude, a prática do boxe, chegando até a ter certo destaque. Seu corpo marcava a presença e a força. Quando chegou à Colônia, exerceu por um tempo a tarefa de xerife ou faxina. O que significava que era responsável por conter outros internos com sua força física. Ele mesmo temia sua força.

De meses em meses, (...), pedia firme:

- Me prende porque eu estou me transformando.

(...)

Andava de um lado a outro lado da cela, passando a mão na cabeça, reclamando da insuportável pressão. Desfiava um rosário de frases desconexas, falava de reis e rainhas de um mundo (ir)real. (Hidalgo, 1996, p. 25)

As transformações lhe acompanharam até o fim. Além de pedir para ficar preso, entrava em um estado de jejum. Comia algumas frutas que os funcionários 
lhe ofereciam e, por vezes, passava a semana movido a copos de água com açúcar. Anunciava: "Vou secar para virar santo" (Hidalgo, 1996, p. 25). E ainda dizia ter cravada uma cruz brilhante em suas costas. Aborrecia-se profundamente se alguém não acreditava ou questionava essa cruz.

\section{Algumas considerações sobre o uso da topologia dos nós}

Lacan iniciou seu percurso na psicanálise a partir da psicose. Com o estruturalismo, tomou os modos de passagem pelo Édipo para nomear as estruturas clínicas e, com isso, nortear os índices para a direção do tratamento. A neurose e a perversão, sendo as estruturas que respondem à afirmação extraída dessa passagem, e as psicoses, sendo as estruturas que, pelo processo de foraclusão, não respondem à afirmação edípica, ficam sem a articulação do Nome-do-Pai.

Nesse momento da construção conceitual, o diagnóstico localiza o modo pelo qual o sujeito responde à sua divisão. Considerando que as psicoses devem ser lidas no plural, Bousseyroux (2014, p. 158, tradução nossa) afirma: "Há condições para a psicose. Não fica louco quem quer. Há condições para que essa escolha da psicose, como escolha da estrutura, se faça." ${ }^{2}$ Assim, pela psicanálise, não há psicose, mas as psicoses, e isso desde o início da releitura que Lacan fez de Freud, haja vista que seu primeiro seminário é sobre As psicoses (Lacan, 1955-1956/1985), no plural. Mesmo os psicóticos devem ser contados um a um. Não haveria uma solução ideal que todos os psicóticos tivessem de atingir.

$\mathrm{O}$ avanço com a topologia dos nós favoreceu principalmente a leitura e a orientação dos tratamentos das psicoses. Até esse momento, era possível pensar as psicoses pelos esquemas, grafos e mesmo pela topologia de superfície. No entanto, com os nós, as estruturas não são abolidas, mesmo que o peso maior não recaia sobre elas. Rithée Cevasco afirma:

A clínica dos nós borromeanos não desconstrói a clínica anterior, por exemplo, a divisão clássica que distingue entre neurose, psicose e perversão a partir da posição do sujeito a respeito da castração (repressão, forclusão e denegação). Não se rechaça essa clínica, porém a clínica borromeana amplia as possibilidades do tratamento das categorias clínicas com outros paradigmas (...) e isso não deixa de ter consequências bem importantes. (Cevasco, 2018, p. 16)

Com essa topologia, temos a entrada de um pensamento clínico em que a divisão não é excluída. Lacan passa, assim, a articular os registros Real, Simbólico

2 No original: "ll ya a des conditions à la psychose. Ne devient pas fou qui veut. Il y a des conditions à ce que le choix de la psychose, comme choix de la structure, se fasse." 
e Imaginário de modo que não haja um Falasser que não tenha esses três sendo articulados de algum modo. O Falasser é, inclusive, introduzido por Lacan justamente nesse momento. Rithée ainda acrescenta:

Parlêtre (Falasser) evoca em francês a fala e a letra e também pode ouvir-se como "pelo o ser" (par l'être) ou "pela a letra" (par la lettre) (...). Se distingue $[$ sic] do sujeito do inconsciente (\$) definido a partir de sua representação pelos significantes. Se trata [sic] do falasser em todas as suas dimensões R, S, I. (Cevasco, 2018, p. 33)

O conceito de Falasser é um efeito do que Lacan trabalhava nesse período com a topologia dos nós. Ele amplia o pensamento clínico e diagnóstico, pois, diferentemente do sujeito dividido, pode ser lido em todas as estruturas. Um psicótico é um Falasser que se amarra de um modo que R, S e I se enodam de uma maneira específica. Bousseyroux apresenta as psicoses como sendo modos de amarração em que há alguma indistinção entre os registros:

Essas indistinções correspondem, quanto ao nó RSI, a uma colocação em continuidade por anexagem: da rodela do real, com aquela do simbólico, para a esquizofrenia; da rodela do imaginário, com aquela do real, para a melancolia; e da rodela do simbólico, com aquela do imaginário, para a mania. Qual nó resulta? É aquele que estrutura a fantasia. A esquizofrenia, a melancolia e a mania têm em comum, se acompanhamos essa hipótese, serem estruturadas como uma fantasia. O que as diferencia é que, no esquizofrênico, o objeto toma a consistência na imagem do corpo autoerotizado, enquanto, no melancólico, ele toma o lugar do Outro simbólico, e no maníaco ele a toma no real do vivente. (Bousseyroux, 2011, p. 103, tradução nossa) $)^{3}$

Para dizer do nó na esquizofrenia, na mania e na melancolia, Bousseyroux utilizará o nó de Whitehead. É a partir desse nó que esse comentador propõe um modo de ler e formalizar esses tipos clínicos dentro das psicoses. Esse nó permite pensar uma continuidade entre dois registros, sendo suportado por um terceiro.

3 No original: "Ces indistinctions correspondent sur le noeud RSI à une mise en continuuité par raboutage : du rond du réel avec celui du symbolique, pour la schizophrénie, du rond de l'imaginaire avec celui du réel, pour la mélancolie, et du noeud du symbolique avec celui de l'imaginaire, pour la manie. Quel noeud en resulte-t-il ? C'est celui qui structure le fantasme. La schizofrénie, la mélacolie et la manie ont en commun, si l'on suit cette hypothèse, d'être structurées comme un fantasme. Ce qui les différencie, c'est que chez le schizophrène l'objet prend consistance dans l'image du corps autoérotisé, alors que chez le mélancolique il la prend su lieu de l'Autre symbolique, et que chez le maniaque il la prend dans le réel du vivant." 
Figura 1. Nó de Whitehead.

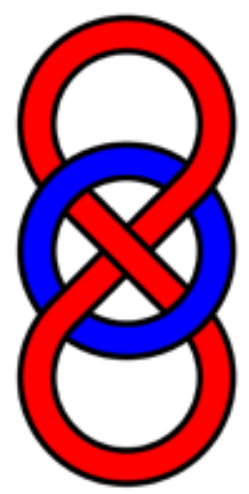

Fonte: Da autora.

Seria, então, o terceiro registro o que faria algum tipo de sustentação desses outros dois que estão em continuidade. Esse nó também poderia dizer da fantasia, como indica a citação, ou da representação da não relação sexual por se tratar da possibilidade de intercâmbio dessas duas rodelas por deformação contínua. Porém, isso não é sinônimo de que a fantasia, como Lacan a concebeu, se aplicaria tal e qual nas psicoses. O nó de Whitehead é aplicado para pensar a fantasia, pois ele passa de uma a outra estrutura de suas rodelas indefinidamente. Para pensar as psicoses, não é do Sujeito e do objeto que se trata, mas dos registros RSI. Assim, muda a leitura desse nó. Um nó trivial, como a amarração dos outros dois em continuidade. Essa continuidade marcando um ponto de cruzamento nela mesma, e dois com o elo que a sustenta.

\section{Bispo nos nós}

Bispo confirma o diagnóstico de esquizofrenia tanto por seu dizer quanto por sua obra. Pelo que diz, ouvimos a presença permanente das vozes, que lhe ordenam a feitura de sua obra e da missão decorrente dessa ordem. Em sua obra, a indistinção palavra e coisa apresenta-se continuamente, literalmente bordeando o insuportável da irrupção do real.

Uma leitura possível considera a arte como o que poderia ter organizado Bispo. Nessa via, Quinet (2006, p. 90) conclui que, "com seu sintoma, Arthur Bispo do Rosário encontra representação no significante: ele é representado por sua obra - letra de gozo (S1) para Deus (S2)". Mas teria o enlace da arte operado como correção do nó de Bispo? 
Pelas falas recolhidas em entrevistas, temos a dimensão das vozes ouvidas por Bispo. Ele diz escutá-las desde pequeno, e no documentário de Hugo Denizart revela que é obrigado a fazer tudo aquilo, que as vozes lhe obrigam e que, se pudesse, não o faria. Ora, sua obra é o fruto dessa submissão ao Outro que lhe ordena. Ele diz: "Jesus Filho (que ele acreditava ser ele mesmo) tem que executar no seu canto, aí embaixo, faça isso e isso. Eu nem falo nada, tenho que executar isso tudo" (Hidalgo, 1996). Efetivamente, sua obra tem uma função de contorno do impossível que a irrupção de sua psicose deixou a céu aberto. Mas, pelo que recolhemos de suas falas, não operava como uma correção.

É possível pensar, a partir da topologia dos nós, que, “mesmo desfeito, o nó pode ainda se refazer. Mesmo o louco normal, aquele que não consegue encontrar o seu lugar porque está fora do nó, pode se encontrar num lugar subjetivo, que seja o do nó paranoico, do nó esquizofrênico, maníaco-depressivo, ou bem ainda sintomático" (Bousseyroux, 2011, p. 106). Usando a ideia do nó de Whitehead exposto anteriormente, proponho pensar em sua arte como um reflexo do modo de amarração na qual Bispo se manteve até o fim; como esse elo imaginário que mantinha, de algum modo, a continuidade real-simbólica estável. Como apresentado no início deste texto, sua relação com sua obra não é a mesma que tinha, por exemplo, James Joyce. Bispo não se nomeia artista e não se apoia nesse nome.

Podemos acompanhar também uma observação feita por Ricardo Resende, curador do Museu Bispo do Rosário, onde se diferencia o processo criativo de Bispo do de outro artista que faz algumas performances semelhantes. Ele escreve:

Como não relacionar essa deambulação de Bispo na sua trajetória até uma igreja no Centro da cidade com a de Arthur Barrio, em 4 dias 4 noites, ${ }^{4}$ de 1970 ?

Barrio saiu em uma caminhada à deriva pelas ruas do Rio de Janeiro, sem se alimentar, sem parar, sem se comunicar, em silêncio, por quatro dias e quatro noites. Seguiu em total devaneio até o esgotamento físico completo. Seria uma forma de loucura do artista?

Porque [sic] Barrio faz arte e Bispo não? A diferença reside no fato de que Barrio decidiu-se pela deambulação e Bispo, não. Bispo foi levado por vozes que o direcionavam àquela igreja pelas tortuosas ruas do Rio de Janeiro. (Resende, 2016, p. 25)

Isso não tira o peso artístico do fazer de Bispo, mas nos abre a questão do lugar desse Falasser em relação aos registros. Barrio decide levar seu corpo à deriva como

4 Performance do artista explicada na sequência do texto. 
experiência performática e, a partir dela, questionar o fluxo, a cidade e o pensamento. Bispo, na abertura real do céu sobre sua cabeça, põe-se pela escrita contínua com esse real a contornar essa irrupção, como bem escreve em um dos estandartes:

\section{EU PRECISO DESTAS}

PALAVRAS - ESCRITA. (Rosário citado por Hidalgo, 1996, p. 151)

O corpo, para Bispo, também tem a marca dessa irrupção real, que, além da aura, é a senha para a entrada de sua cela e tem as transformações como eventos reais. Ele mesmo pede para ser preso, porque está se transformando. E coloca seu corpo em abstinência de alimento e de contato com as pessoas. Sobre isso, temos ainda com Bousseyroux (2014, p. 212, tradução nossa): “A palavra, desmetaforizada, encarna-se na carne. Assim, a esquizofrenia é o verbo que se faz carne (donde a frequência dos delírios crísticos). Em outras palavras, é o simbólico que se faz real."

\section{0 que sustentou sua arte?}

Lendo sua biografia, um enigma ainda se desenha: enquanto os pacientes tinham seus bens confiscados diariamente, Bispo montava suas assemblages e seus bordados sem ser incomodado. Seria preciso certa complacência da estrutura manicomial. Acompanhando sua biografia, entendemos que é preciso incluir outros elementos que agiram ali para que Bispo pudesse construir seu trabalho.

Bousseyroux propõe que, no caso Aimée, sua irmã Elise teria funcionado como um quarto elemento de um nó que manteve Aimée, sua mãe e sua tia estabilizadas. Proponho pensar que, no caso de Bispo, não foi sua arte que o manteve. Do lado do hospital, não haveria suporte caso não houvesse antes um representante que possibilitasse seu trabalho dentro da instituição. Proponho que o que pôde suportar seu trabalho dentro de sua esquizofrenia foram os antigos patrões e a influência deles no hospital. Do próprio Bispo, havia seu corpo como força de contenção dos outros internos, o que não seria suficiente para manter a complacência da estrutura hospitalar com suas construções.

Podemos acompanhar que, em Bispo, o Real das vozes que lhe ordenam, da cruz que brilha em suas costas está em continuidade com a tarefa impossível de inventariar o mundo. O Imaginário intervém nessa continuidade, fazendo com que ele se estabeleça em uma estabilidade instável. Nos momentos em que sentia que sofreria uma "transformação", era o corpo que era convocado, ficando agitado, pressionado e privado de alimento para se manter em sua missão. Essas transformações têm o peso da instabilidade da amarração de Bispo.

5 No original: "Le mot, démétaphorisé, s'incarne dans la chair. Ainsi, la schizophrénie, c'est le verbe qui se fait chair (d'où la fréquence des delires christiques). Autrement dit, c'est le symbolique qui se fait réel." 
Em sua arte, há a continuidade entre Real e Simbólico. Palavra e coisa não se distinguem em seu escritos e objetos. A mediação passa pelo imaginário do corpo, além de vestir o manto com as inscrições da continuidade Real-Simbólica, trabalhando freneticamente quando as transformações irrompem. Temos, assim, a instabilidade que é para um Falasser que se amarra ao modo contínuo do nó da fantasia (o nó de Whithead).

Bispo recebeu um suporte no qual sua estrutura não podia apoiá-lo. Seus patrões no Rio de Janeiro não patologizavam os fenômenos que aconteciam com ele. Ele continuava a trabalhar para eles durante as internações, e eles até mesmo "dialogavam" com os fenômenos de sua psicose - como apresentado no diálogo do dr. Bomfim sobre sua aura. Isso o sustentou durante muito tempo antes da última e derradeira internação na Colônia.

Assim, para que o trabalho de Bispo pudesse ser produzido e construído nas condições do manicômio, ele estava apropriado do lugar daquele que trabalhou para os Leones. Isso, somado à força de sua presença no hospital, permitiu que o trabalho seguisse seu curso.

O nó que a arte proporcionou não parece ter sido na direção da estabilização de Bispo, mas na da modificação do espaço onde ele estava instalado. Quando Frederico de Moraes declarou que aquilo que Bispo fazia podia ser inserido na história da arte, nomeou sua obra e a enlaçou a outros nomes. A arte, na figura desse crítico, fez com que algo se reconfigurasse: Bispo passa a ser nomeado artista, o hospital passa a nomear-se Museu e as oficinas terapêuticas passam a ser ateliês de arte.

Esse efeito de (re)nomeação a partir da intervenção do crítico e pela arte operou para além da estabilização de Bispo, pois até o fim ele experimentava as transformações. A tentativa de tratamento feita por uma estagiária desembocou em um modo de erotomania representada solenemente em uma instalação. Quando Rosângela, a estagiária, trabalhava com ele sua saída, Bispo montou em um dos cubículos uma cama de casal com o Manto da Apresentação, uma camisola branca e o quarto arrumado para representarem Romeu e Julieta - cena que não foi representada. Rosângela saiu de seu estágio. Bispo viveu mais oito anos sem, contudo, ir às exposições de suas obras.

Vemos, assim, que houve com a arte uma modificação do lugar físico (hospital e oficinas) e do lugar de Bispo (artista). Poderíamos pensar, com isso, que, durante a vida inteira, Bispo manteve-se estabilizado, pelo apoio do nome de seus antigos patrões, a um modo de continuidade esquizofrênica. O nome "artista" reverberou para além do sujeito em questão. Como psicótico, ele não se apropriou desse nome de forma a corrigir a continuidade esquizofrênica, mas se manteve nela até o fim. No entanto, esse nome ressignificou os laços do espaço físico do Hospital e das 
Oficinas, permitindo ecos para além da história de Bispo. Acompanhando seu caso, podemos pensar que a arte pôde nomear o evento Real que a obra de Bispo expôs. A aposta seria de que as instituições psiquiátricas pudessem suportar o que de Real escapa e se apresenta em casos como o desse artista, permitindo, assim, que os psicóticos como falasseres possam se contar e encontrar seu modo próprio de lidar com o Real que lhes irrompe e invade. Com uma escuta diferenciada e outro modo de nomeação, talvez tenhamos menos pacientes cronificados e - quem sabe? - outros como Bispo.

\section{Referências bibliográficas}

Bousseyroux, M. (2011). Les maladies de l'indistinction. In M. Bousseyroux. Au risque de la topologie et de la poesie: élargir la psychanalyse. Toulouse: Érès.

Bousseyroux, M. (2014). Condition de la psychose. In M. Bousseyroux. Lacan le borroméen: creuser le noeud. Toulouse: Érès.

Cevasco, R. (2018). Paso a paso... Hacia una clinica borromea (Jorge Chapuis, Col.) (Vol. 1). Barcelona: Centro de Investigación Psicoanálisis y Sociedad. Documento interno.

Hidalgo, L. (1996). Arthur Bispo do Rosário: o senhor do labirinto. Rio de Janeiro: Rocco.

Lacan, J. (1985). O seminário, livro 3: as psicoses. Rio de Janeiro: Jorge Zahar. (Trabalho original publicado em 1955-1956)

Lacan, J. (2007). O seminário, livro 23: o sinthoma. Rio de Janeiro: Jorge Zahar. (Trabalho original publicado em 1975-1976)

Quinet, A. (2006). Psicose e laço social: esquizofrenia, paranoia e melancolia. Rio de Janeiro: Jorge Zahar.

Resende, R. (2016). Constelação Bispo: notas sobre a multiplicidade do ato criativo. In Catálogo da exposição Das virgens em cardumes e da cor das auras (Daniela Labra, Org.). São Paulo: WMF Martins Fontes.

Recebido: 10/10/2018

Aprovado: 07/12/2018 